\title{
Metallic Surface Considered from a Study of Organic Corrosion Inhibitors
}

\author{
Seiichi Fujii, Ryoji Sugano and Kenzo Kobayashi \\ Chemical Laboratory, Keio University*
}

In the previous papers, the authors proposed that organic corrosion inhibitors could be adsorbed on metal surface by displacing adsorbed water. For example, amine acts as an inhibitor for metals in corrosive media in the following manners.

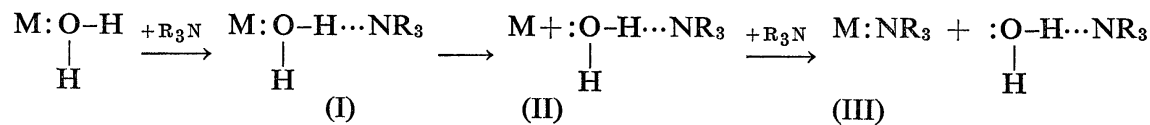

When the inhibitor is insufficiently added to the media, an active site, which is given by $M$ at the stage (II), may be exposed to corrosives and subsequently the metallic corrosion may proceed. In this report, the corrosion and the corrosion inhibition processes of $\mathrm{Fe}$ and $\mathrm{Al}$ in the state corresponding to the stage (II) were examined in aqueous and non-aqueous corrosive media with the amine inhibitor. The reaction of $\mathrm{Fe}$ or $\mathrm{Al}$ with alkyl bromide in the non-aqueous media took place by the addition of $\mathrm{N}, \mathrm{N}$-dimethyloctylamine at about $10^{-5}$ mole/g-metal. $\mathrm{Al}$ was corroded to more extent in $0.05 \mathrm{~N}$ aqueous alkaline solution with $10^{-5} \mathrm{~mole} / \mathrm{g}-\mathrm{Al}$ of the amine than in the uninhibited solution. In each case the metallic corrosion was most promoted with the approximately equal amount of the amine and the reaction was completely inhibited by the addition of amine at $10^{-3} \mathrm{~mole} / \mathrm{g}$-metal. Moreover, water could inhibit the reaction in the non-aqueous media. In the aqueous media as well as in the non-aqueous media, water might be an inhibitor for the metal. But, because of being strongly associated with bulk molecules in general, water may not be adsorbed on the metal in the aqueous media, even if the electron-accepting sites may be brought about by the desorption of the adsorbed water.

\section{Introduction}

In the previous report, ${ }^{1 \prime}$ the authors postulated that organic corrosion inhibitors could be adsorbed on metal in two ways, one by electrondonation and the other by protonation. For example, primary amine can be adsorbed on the metal in such manners as

$$
\begin{aligned}
& \mathrm{M}+\mathrm{RNH}_{2} \longrightarrow \mathrm{M}: \mathrm{NH}_{2} \mathrm{R} \text { and } \\
& \mathrm{M}+\mathrm{RNH}_{2} \longrightarrow \mathrm{M}: \mathrm{HNHR}
\end{aligned}
$$

The former is by the donation of an electron pair on $\mathrm{N}$-atom of the amine, and the latter by the protonation of amino group. In other words, the metal can accept a pair of electrons from the inhibitor molecule and can donate a pair of electrons to an active hydrogen of the inhibitor. But these two characteristics may often lead to the molecular association as illustrated below,<smiles>[R]NC(N[R])N[Z1]([R])[H]</smiles>

This association reduces its inhibitive effect on the metallic corrosion.

A typical compound which has these two characteristics is water molecule existing in the air. Consequently, water should be adsorbed on the metal as illustrated in the following formulas, ${ }^{2)}$

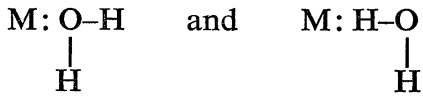

The former water, as already described in the authors' paper, ${ }^{3)}$ should be changed by displacement of the corrosion inhibitor when it comes contact with the metal.
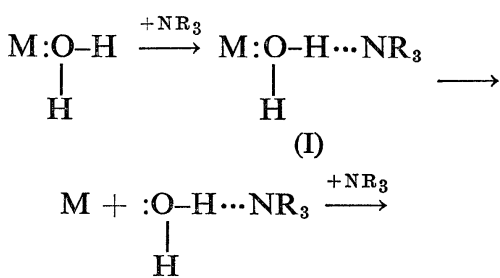

(II)<smiles>[R16][14CH2]O[14CH3]</smiles> 
It has not been made clear yet whether the latter water would be displaced with the inhibitor molecule or not. Then now, authors must presume either of the two following formulas when the metal is to come contact with proton-donating inhibitor.

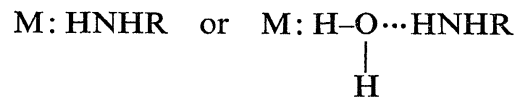

From the standpoint of taking the electrondonating inhibitor, the metal should be strongly electron-accepting when an inhibitor pulls the adsorbed water off from the metal. In other words, the metal should become active when the adsorbed water departs from the surface.

In order to clarify the active sites on the metal, limited amounts of the electron-donating inhibitors were adopted to realize the stage (II) in the equation (1) and to make the metal surface react with alkyl halide which is strongly electrondonating.

This study was undertaken to clarify the knowledge of the metal surface reactivity and adsorption mechanism of organic corrosion inhibitors. Shaw reported on the reaction of $\mathrm{CCl}_{4}$ with aluminum pieces which were cut in $\mathrm{CCl}_{4} \cdot{ }^{4}{ }^{1} \mathrm{He}$ observed that aluminum was very active and reacted with $\mathrm{CCl}_{4}$ at room temperature. In the authors' experiments aluminum-chips, prepared in isooctane not to contact with the air, reacted easily with $\mathrm{CH}_{3} \mathrm{I}$.

\section{Experimental}

\subsection{Materials}

$A l$ : Coupons of $99.99 \% \mathrm{Al}, 20 \times 50 \times 0.3 \mathrm{~mm}$, were immersed in aqueous alkaline solution and were washed with deaerated water. Soon after these procedures, they were dried in a vacuum desiccator. Aluminum powder $(99.4 \%$ purity, Tokyo Kasei G.R.) was dipped in $1.2 \%$ aqueous alkaline solution at $20^{\circ} \mathrm{C}$ for $5 \mathrm{~min}$ and washed with deaerated water under nitrogen atmosphere and then dried in a vacuum desiccator.

$\mathrm{Fe}$ : Commercial reduced-iron powder $(95 \%$ purity, MERCK, proanali) was adopted. On storage, it was kept in a helium-filled desiccator.

Other reagents: As the corrosives, $n$-hexylbromide $\left(88^{\circ} \mathrm{C} / 90 \mathrm{mmHg}\right)$, and $n$-butylbromide $\left(101^{\circ} \mathrm{C}\right)$ were used. As the inhibitors, N,Ndimethyloctylamine $\left(80^{\circ} \mathrm{C} / 90 \mathrm{mmHg}\right)$ and, as the solvents $n$-hexane, isooctane and diethylether were used. They were carefully dehydrated and purified. Absence of impurity in each reagent was determined with the I.R. spectrum or the chromatogram, respectively.

\subsection{Corrosion tests}

Reactions of the metal with alkyl halide were carried out in an apparatus which is schematically illustrated in Fig. 1. As the corrosion products of these reactions were easily decomposed in contact with air or moisture, the apparatus was dully dried by means of heating and passing dry helium gas through before use. After the apparatus was cooled down while helium gas passed through, the metal powder and alkyl halide solution were introduced into a three necked flask (I) in Fig. 1, and the flask was gently warmed. In the case of aluminum, the reaction temperature was kept at $80^{\circ} \mathrm{C}$ and in the case of iron at the boiling point of the solution. After the temperature of the solution was fixed, helium gas supply was stopped and the solution was kept airtight. Under these conditions the reaction was continued for $6 \mathrm{hrs}$ as described in 2.2.2.

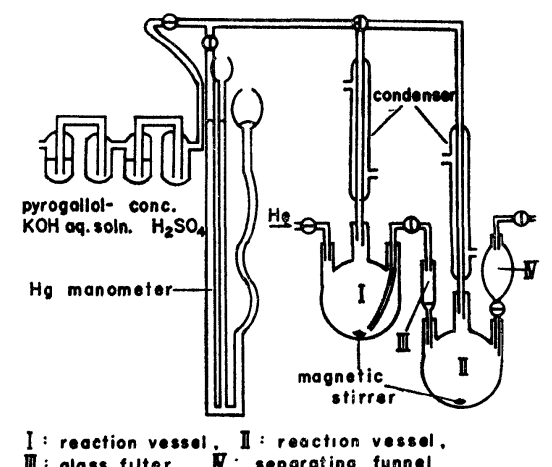

Fig. 1. Apparatus for the reaction of metal powder with alkyl halide.

\subsubsection{Measurement of the induction period in the reaction of aluminum with $\mathrm{C}_{6} \mathrm{H}_{13} \mathrm{Br}$}

Isooctane $(9 \mathrm{~g}), n$-hexylbromide $(10 \mathrm{~g})$, and aluminum powder $(0.2 \mathrm{~g})$ were mixed in the flask (I). After a while, the reactions took place. The initiation of the reaction could be observed from the color change of the solution. The time needed for the initiation was regarded as a measure of the induction period. Effect of the amine addition in the solution on the induction period was examined.

\subsubsection{Reactions of iron with $\mathrm{C}_{4} \mathrm{H}_{9} \mathrm{Br}$}

The reaction of the reduced-iron powder $(5 \mathrm{~g})$ with $\mathrm{C}_{4} \mathrm{H}_{9} \mathrm{Br}(20 \mathrm{~g})$ was carried out at the boiling point of the solution. No color change of the solution was observed. Consequently, the authors limited the reaction time to 6 hours and examined 
the effect of the amine addition on the amount of corroded iron. After the reaction was over, the product was separated from residual powder through a filter equipped with the reaction vessel by the aid of helium gas pressure. The residual powder in the filter was repeatedly washed with fresh ether, and ether-soluble part was collected in the other flask (II) in Fig. 1. To ether-soluble part, in which there might be an organoiron compound as the reaction product of iron, deaerated water was slowly introduced through a separating funnel equipped with the flask (II). Decomposition occurred and gas was evolved. The volume of the collected gas was measured by a Hg-manometer set in the apparatus. And then, the gas was chromatographically analyzed. The chromatographic conditions employed were as follows:

Column. silica gel $2 \mathrm{~m} \times 3 \mathrm{~mm} \phi$

Temp. $\quad 110-180^{\circ} \mathrm{C}\left(10^{\circ} \mathrm{C} / \mathrm{min}\right)$

Carrier gas $\mathrm{He}$

and its flow rate. $30 \mathrm{ml} / \mathrm{min}$

After the gas was completely evolved, further $50 \mathrm{ml}$ of water was added. And then, whole liquid was taken out of the apparatus. The ether-soluble part and the water-soluble part were separately analyzed.

Determination of $\mathrm{Fe}^{2+} .^{5} \quad \mathrm{Fe}^{2+}$ ion was found in the water layer. After adjusting $\mathrm{pH}$ value of the solution at 3.5 , the solution was colored with $o$ phenanthroline under inhibition of $\mathrm{Fe}^{2+}$ oxidation with hydroquinone. The concentration of $\mathrm{Fe}^{2+}$ was determined colorimetrically by means of the absorption band at $540 \mathrm{~m} \mu$.

Determination of $\mathrm{Br}^{-6)}$ Concentration of $\mathrm{Br}^{-}$ was determined by Fajans' method. The solution was titrated with $0.01 \mathrm{M} \mathrm{AgNO}_{3}$ aqueous solution by using fluoresceine as an indicator.

Treatment of the ether-soluble part. The ether solution was concentrated by evaporation of the solvent. The concentrated solution was chromatographically analyzed and nothing of the reaction product was detected. Especially, nbutanol, presence of which was expected from hydrolysis of $\mathrm{C}_{4} \mathrm{H}_{9} \mathrm{Br}$, could not be detected.

\section{Result and Discussion}

$\mathrm{CCl}_{4}$ in which aluminum coupon was dipped was boiled under a reflux condenser. After a while, a violent reaction was observed. ${ }^{7)}$ It was found that the reaction took place after an induction period which depended on the reaction temperature as shown in Table 1.

From the observation, the reaction seemed to
Table 1. Relationship between reaction temperature and induction period of the reaction of $\mathrm{Al}$ with $\mathrm{CCl}_{4}$.

\begin{tabular}{cc}
\hline Reaction temperature & Induction period \\
\hline $76.7^{\circ} \mathrm{C}$ & $5 \mathrm{~min}$ \\
70 & 10 \\
65 & 15 \\
60 & 20 \\
55 & 38 \\
50 & 95 \\
40 & 5 day \\
\hline
\end{tabular}

initiate at the time when water was codistilled with $\mathrm{CCl}_{4}$ and water was absent in the liquid $\mathrm{CCl}_{4}$. As the result of the induction period measurement conducted with aluminum coupons at the fixed temperature was fairly scattered, the authors tried the measurement at $80^{\circ} \mathrm{C}$ in isooctane with aluminum powder and $\mathrm{C}_{6} \mathrm{H}_{13} \mathrm{Br}$ instead of aluminum coupon and $\mathrm{CCl}_{4}$. And it was found that the addition of $10^{-5} \mathrm{~mole} / \mathrm{g}-\mathrm{Al}$ of dimethyloctylamine to the reaction system reduced the induction period. In Fig. 2, the relation between the induction period and amount of the amine is shown. With $10^{-5} \mathrm{~mole} / \mathrm{g}-\mathrm{Al}$ of $\mathrm{C}_{8} \mathrm{H}_{17} \mathrm{~N}\left(\mathrm{CH}_{3}\right)_{2}$, the reaction of aluminum with $\mathrm{C}_{6} \mathrm{H}_{13} \mathrm{Br}$ was rather promoted than that without $\mathrm{C}_{8} \mathrm{H}_{17} \mathrm{~N}\left(\mathrm{CH}_{3}\right)_{2}$, and a little more dosage of the amine prolonged the period. The reaction was completely inhibited with $10^{-4}$ mole/g-Al of $\mathrm{C}_{8} \mathrm{H}_{17} \mathrm{~N}\left(\mathrm{CH}_{3}\right)_{2}$. The accelerated corrosion would be caused by removement of the adsorbed water through the formation of hydrogen bond with limited amounts of the inhibitor. The desorption of water leaves the

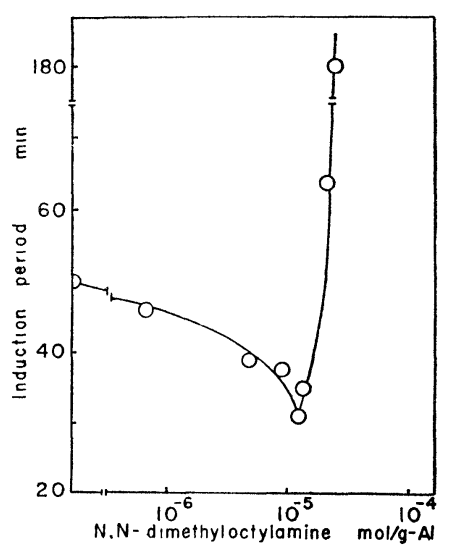

Fig. 2. Effects of N,N-dimethyloctylamine addition on induction period of the corrosion of $\mathrm{Al}$ with hexylbromide in isooctane at $80^{\circ} \mathrm{C}$. 
electron-accepting sites on the metal where electrondonating corrosives can attack without hindrance of inhibitors. This process can be shown as follows.<smiles></smiles>

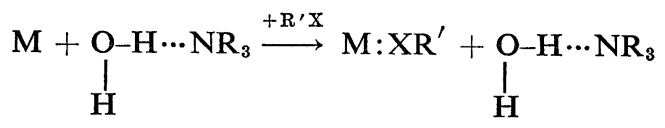

Halogen compound $\mathrm{R}^{\prime} \mathrm{X}$ is adsorbed on the metal owing to its electron donation as shown at the stage (III) in equation (2) and subsequently drags a metallic atom out of the crystal.

Two organoaluminum compounds, $\mathrm{R}_{2} \mathrm{AlX}$ and $\mathrm{RAlX}_{2}$, are expected as the corrosion products in this reaction. Hence, the authors chose iron, instead of aluminum, expecting a simpler product. With or without the solvents iron and $\mathrm{C}_{4} \mathrm{H}_{9} \mathrm{Br}$ reacted at various temperatures with the aid of $\mathrm{C}_{8} \mathrm{H}_{17} \mathrm{~N}\left(\mathrm{CH}_{3}\right)_{2}$ as the remover of water which was adsorbed by the electron donation.

The relations between the amounts of corroded iron and added $\mathrm{C}_{8} \mathrm{H}_{17} \mathrm{~N}\left(\mathrm{CH}_{3}\right)_{2}$ are shown in Fig. 3 and Fig. 4. The results given in Fig. 3 are obtained in ether and without solvent. In Fig. 4, the data are shown in the case of hexane as a non-polar solvent. The amount of $\mathrm{Fe}^{2+}$ ion was varied with the reaction temperature and the sort of solvents, while the amounts of added amine at

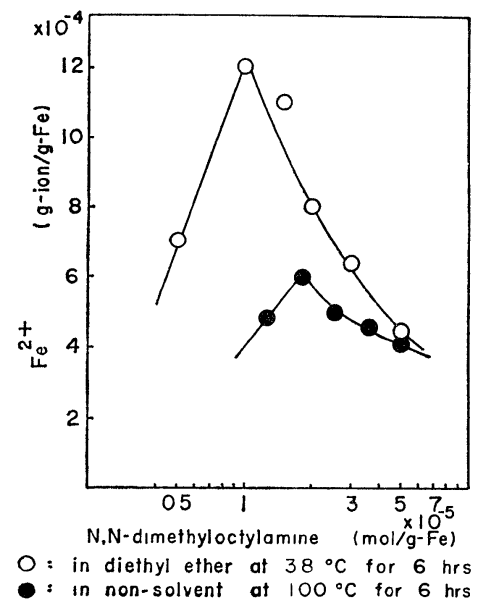

Fig. 3. Effects of N,N-dimethyloctylamine on the reaction of commercial reduced-iron powder with butylbromide.

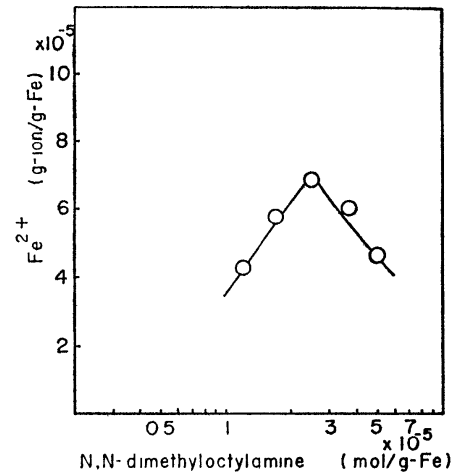

Fig. 4. Effects of N,N-dimethyloctylamine on the reaction of commercial reduced-iron powder with butylbromide in $n$-hexane at $70^{\circ} \mathrm{C}$ for 6 hours.

the maximum value of $\mathrm{Fe}^{2+}$ ion were almost equal in all cases $\left(1 \times 10^{-5}-2.5 \times 10^{-5} \mathrm{~mole} / \mathrm{g}-\mathrm{Fe}\right)$. The reaction was markedly inhibited by further addition than these amounts of amine. Larger amount of the corrosion product was found in ether than in hexane and without solvent and the least in hexane. These might be due to difference in solubility of the organoiron compound in each solvent. In ether the compound could be soluble as the etherate, and the fresh surface of iron was always left to contact with the bromide. But in the non-polar solvent, because of being less soluble and of remaining on the metal surface, the compound blocked the metal to contact with the bromide. In any case, the limited amounts of the inhibitor accelerated the corrosion of iron in nonaqueous media. The reaction might proceed as following equations.

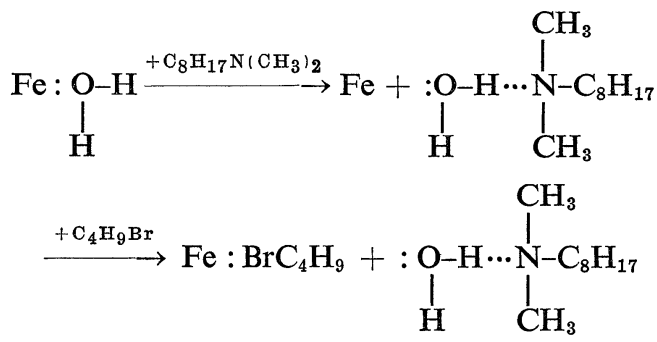

Butylbromide displaced the adsorbed water and could not stand as it was in that state, because Fe: $\mathrm{BrC}_{4} \mathrm{H}_{9}$ might leave the metal as a corrosion product.

As the corrosion product could be soluble in ether, this solvent was used to extract the product. The ether extract was decomposed with water and the evolved gas was identified with $\mathrm{C}_{4} \mathrm{H}_{10}$. The 
Table 2. Analytical results.

\begin{tabular}{lcccccc}
\hline Solvents & $\begin{array}{c}\mathrm{C}_{8} \mathrm{H}_{17} \mathrm{~N}\left(\mathrm{CH}_{3}\right)_{2} \\
\mathrm{~mol} / \mathrm{g}-\mathrm{Fe}\end{array}$ & $\begin{array}{c}\text { Reaction } \\
\text { temp. } \\
{ }^{\circ} \mathrm{C}\end{array}$ & $\begin{array}{c}\mathrm{Fe}^{2+} \\
\text { g-ion/g-Fe }\end{array}$ & $\begin{array}{c}\mathrm{Br}^{-} \\
\text {g-ion } / \mathrm{g}-\mathrm{Fe}\end{array}$ & $\begin{array}{c}\mathrm{C}_{4} \mathrm{H}_{10} \\
\mathrm{ml} / \mathrm{g}-\mathrm{Fe}\end{array}$ & $\mathrm{Fe}^{2+} / \mathrm{Br}^{-}$ \\
\hline Ether & $1 \times 10^{-5}$ & 38 & $1.2 \times 10^{-3}$ & $1.6 \times 10^{-3}$ & & 0.75 \\
$n$-Hexane & $2.5 \times 10^{-5}$ & 70 & $6.8 \times 10^{-5}$ & $6.7 \times 10^{-5}$ & & 1.02 \\
& $1.8 \times 10^{-5}$ & 100 & $6.0 \times 10^{-4}$ & $5.6 \times 10^{-4}$ & $14.2^{*}$ & 1.07 \\
\hline
\end{tabular}

*: at N.T.P.

amounts of $\mathrm{Fe}^{2+}$ and $\mathrm{Br}^{-}$in the water-soluble part were determined. The results summarized in Table 2 were obtained when the corrosion reactions were most accelerated with about $1 \times$ $10^{-5} \mathrm{~mole} / \mathrm{g}-\mathrm{Fe}$ of amine.

From the data in Table 2, the ether-soluble compound might be empirically formulated as $\mathrm{C}_{4} \mathrm{H}_{9} \mathrm{FeBr}$ (or $\left.\left(\mathrm{C}_{4} \mathrm{H}_{9}\right)_{2} \mathrm{Fe} \cdot \mathrm{FeBr}_{2}\right)$. And its decomposition reaction with water might proceed as the following equation.

$$
\mathrm{C}_{4} \mathrm{H}_{9} \mathrm{FeBr}+\mathrm{H}_{2} \mathrm{O} \longrightarrow \mathrm{C}_{4} \mathrm{H}_{10}+\mathrm{FeBr}(\mathrm{OH})
$$

From the equation, the following values are obtained for each component.

$$
\begin{array}{ll}
\mathrm{C}_{4} \mathrm{H}_{10} & 13.4 \mathrm{ml} \text { (at NTP) } \\
\mathrm{Fe}^{2+} & 6.0 \times 10^{-4} \text { (g-ion/g-Fe) } \\
\mathrm{Br}^{-} & 6.0 \times 10^{-4} \text { (g-ion/g-Fe) }
\end{array}
$$

From the analysis of the ether-soluble compound, only $\mathrm{Fe}^{2+}$ was detected as a cation. Consequently, the authors can refer to Grignard's reagent concerning magnesium, and from the observation the organoferrous compound can be expected to be a similar type to Grignard's compound. Grignard's reaction can catalytically be promoted with $\mathrm{N}, \mathrm{N}$-dimethylaniline in hydrocarbon solvent, ${ }^{8)}$ and this reaction can also be with the limited amounts of the amine. Grignard's reaction is generally carried out in ether which can remove the adsorbed water from the metal as described below,

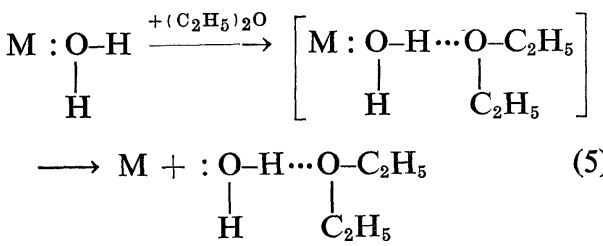

The reaction of iron could not be promoted in ether without the amine. In this case, ether would liberate the adsorbed water but ether-hydrate was so unstable in boiling ether to be decomposed to each component. The liberated water could be adsorbed again on iron to protect it against the bromide, as iron is more attractive for water than boiling ether. In the presence of $\mathrm{C}_{8} \mathrm{H}_{17} \mathrm{~N}\left(\mathrm{CH}_{3}\right)_{2}$ in ether, amine-hydrate $\mathrm{O}-\mathrm{H} \cdots \mathrm{NC}_{8} \mathrm{H}_{17}\left(\mathrm{CH}_{3}\right)_{2}$ might $\mathrm{H}$

be stable in boiling ether and there was no free water which could be adsorbed again on iron. Organoferrous compound would thus be produced by direct coupling of iron and the bromide. In a word, the liberated water may hardly be adsorbed on magnesium in ether, while the water could easily be adsorbed on iron. For the liberated water in boiling ether, iron may be more attractive than magnesium. Amine and water are hydrogen-bridged in ether but each of them is essentially attracted by the electron-accepting site on the metal. In this condition both are coupled and the couple may not be adsorbed on the metal. Consequently, excess of amine or water may be adsorbed on the metal to protect the metal against the corrosion. This inhibition may be kept up to the critical adsorption temperature-the authors expect $120^{\circ} \mathrm{C}$ for nitrogen compounds and about $50^{\circ} \mathrm{C}^{91}$ for oxygen compounds.

When the adsorbed water and the inhibitor are just equimolecular, the reaction of iron with $\mathrm{C}_{8} \mathrm{H}_{17} \mathrm{Br}$ violently takes place. But amine or water in excess is attracted to iron and statisfies their electron-accepting nature. This satisfaction brings about the complete corrosion inhibition of iron. The complete inhibition with amine is well known. The dissociated water in boiling ether can inhibit iron corrosion, as the critical adsorption temperature of oxygen compound on metals is to be about $50^{\circ} \mathrm{C}$. Accordingly, the corrosion tests of iron in ether which held the dissociated water were conducted to verify water acting as a corrosion inhibitor. Water-saturated ether was added to the reaction system in which iron corrosion was most accelerated with the inhibitor, and it was examined whether water was available as an inhibitor in ether or not. In the experiments the amount of $\mathrm{C}_{8} \mathrm{H}_{17} \mathrm{~N}\left(\mathrm{CH}_{3}\right)_{2}$ was $1.5 \times 10^{-5} \mathrm{~mole} / \mathrm{g}-\mathrm{Fe}$. In measuring amount of water the authors took no account of the adsorbed 
water on the metal, because this water should be restrained by the hydrogen-bridge with the amine and should not act as the inhibitor in ether. This behavior of the water molecule could be given as following equations:

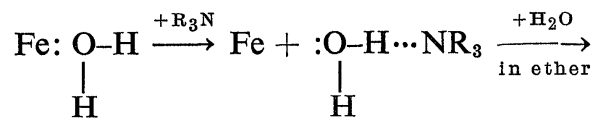

$$
\begin{aligned}
& \mathrm{Fe}: \underset{\mathbf{H}}{\mathrm{O}-\mathrm{H}}+:\left.\right|_{\mathbf{H}} ^{\mathrm{O}}-\mathrm{H} \cdots \mathrm{NR}_{3}
\end{aligned}
$$

Fig. 5 shows relation between the amount of corroded iron and added water which was determined from I.R. spectrum of the water-saturated ether. Water of $10^{-2} \mathrm{M}$ could inhibit iron corrosion with $\mathrm{C}_{4} \mathrm{H}_{9} \mathrm{Br}$ in ether. In non-aqueous media water could be considered such an effective inhibitor as amine.

The reactions taking place in ether were referred to Grignard's ones. As to magnesium the adsorbed water may be easily removed with ether and the sites where the water is desorbed can not be repaired with the electron-donating substance in the solution, while the sites on iron can be easily

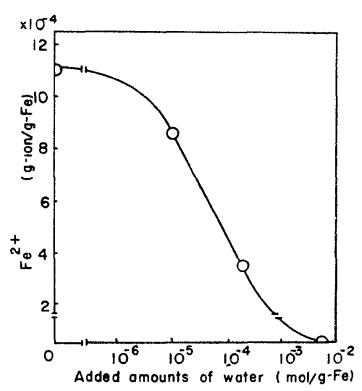

Fig. 5. Effects of water addition on the reaction of commercial reduced iron with butylbromide in diethylether containing $1.5 \times$ $10^{-5}$ mole/g-Fe $\mathrm{N}, \mathrm{N}$-dimethyloctylamine.

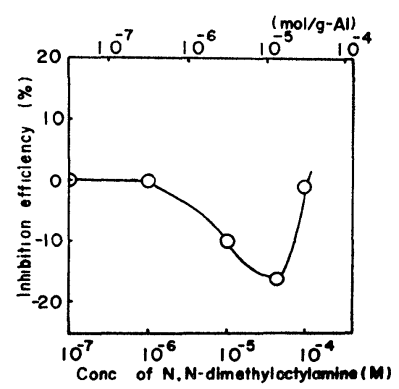

Fig. 6. Stimulative effect of N,N-dimethyloctylamine on the corrosion of $99.9 \% \mathrm{Al}$ in $0.05 \mathrm{~N} \mathrm{NaOH}$ aq. solution at $50^{\circ} \mathrm{C}$. repaired. Being present in the solution, amine may restrain the desorbed water from adsorbing on iron again.

The metallic corrosion in non-aqueous media may come about at the electron-accepting sites where the water is desorbed. The electrondonating substances may compete for the adsorption onto the sites of metal with the desorbed water which is not bound in the solution. And when stronger electron-donating substances can get the sites instead of water, the metallic corrosion can be brought about.

The reaction of metals in non-aqueous media has been discussed above. In aqueous media, it was reported that metals are acceleratedly corroded with small amounts of inhibitors. ${ }^{10)}$ The adsorbed water on metals seems to play an important role in aqueous media. For example, in $0.05 \mathrm{~N} \mathrm{NaOH}$ aqueous solution aluminum was acceleratedly corroded with about $10^{-5}$ mole $/ \mathrm{g}-\mathrm{Al}$ of octylamine. And by further addition, aluminum was protected (Fig. 6). This showed that the sites where the adsorbed water was removed with the amine could not be repaired from the bulk water. The bulk water should associate by the formation of hydrogen bond. This water would hardly form the dissociated water molecule which could be adsorbed on the metal.

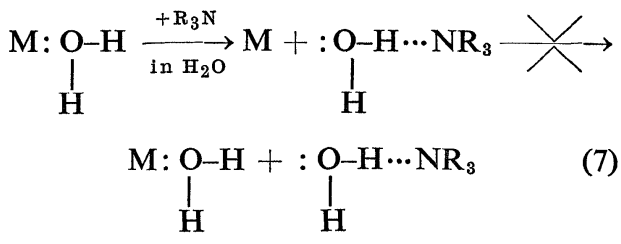

In aqueous solutions there are many corrosives which can pull the adsorbed water off without heating and attack the sites by the donation of electron pairs before the sites are repaired with water.

\section{Conclusion}

Water is adsorbed on the metallic surface in the air, and the adsorbed water protects the metal against corrosion up to the critical adsorption temperature. When this water is desorbed and the sites are repaired neither with the dissociated water nor with inhibitors, the metallic surface would be active. Water, one of the natural inhibitors, plays an important role in aqueous media as well as in non-aqueous media. When there cannot be expected to be the molecular water in the media, the metallic surface is almost unable 
to be repaired. As a consequence, the surface discloses its electron-accepting sites to the corrosives.

(Received October 3, 1973)

\section{References}

1) K. Kobayashi \& S. Fujii: "Proceedings of 3rd European Symposium on Corrosion Inhibitors," p. 253, Univ. Ferrara (1971).

2) S. Fujii, M. Morozumi \& T. Kondo: Boshoku Gijutsu, 20, 273 (1971).

3) S. Fujii \& K. Kobayashi: "Proceedings of 2nd E.S.C.I.," p. 829 (1966).

4) M. C. Shaw: J. Appl. Mech., 15, 37 (1948).
5) R. F. Milton \& W. A. Waters: "Methods of Quantitative Microanalysis," p. 302, Arnold, London (1955).

6) N. H. Furman: "SCOTT's Standard Methods of Chemical Analysis (5th ed.)," Vol. 1, p. 273, Nostrand, New York (1925).

7) M. Stern \& H. Uhlig: J. Electrochem. Soc., 106, 185 (1959).

8) J. Liftschitz: Z. Phys. Chem., 102, 395 (1922).

9) S. Fujii \& K. Kobayashi: Boshoku Gijutsu., 14, 449 (1965).

10) I. N. Putilova: "Proceedings of 3rd I.C.M.C.," Vol. 2, p. 32, Moscow (1966); I. N. Zucchini, F. Zucchi \& G. Tranbanelli: "Proceedings of 3rd E.S.C.I.," p. 577, Univ. Ferrara (1971); G. Davolio \& E. Soragni: ibid., p. 119. 